\title{
Mental Health Disparities Within the LGBT Population: A Comparison Between Transgender and Nontransgender Individuals
}

\author{
Dejun Su, ${ }^{1,2, *}$ Jay A. Irwin, ${ }^{3}$ Christopher Fisher, ${ }^{4}$ Athena Ramos, ${ }^{1}$ Megan Kelley, ${ }^{5}$ \\ Diana Ariss Rogel Mendoza, ${ }^{6}$ and Jason D. Coleman ${ }^{7}$
}

\begin{abstract}
Purpose: This study assessed within a Midwestern LGBT population whether, and the extent to which, transgender identity was associated with elevated odds of reported discrimination, depression symptoms, and suicide attempts.

Methods: Based on survey data collected online from respondents who self-identified as lesbian, gay, bisexual, and/or transgender persons over the age of 19 in Nebraska in 2010, this study performed bivariate t- or chisquare tests and multivariate logistic regression analysis to examine differences in reported discrimination, depression symptoms, suicide attempts, and self-acceptance of LGBT identity between 91 transgender and 676 nontransgender respondents.

Results: After controlling for the effects of selected confounders, transgender identity was associated with higher odds of reported discrimination ( $\mathrm{OR}=2.63, p<0.01)$, depression symptoms ( $\mathrm{R}=2.33, p<0.05)$, and attempted suicides $(\mathrm{OR}=2.59, p<0.01)$ when compared with nontransgender individuals. Self-acceptance of LGBT identity was associated with substantially lower odds of reporting depression symptoms $(O R=0.46, p<0.001)$.

Conclusion: Relative to nontransgender LGB individuals, transgender individuals were more likely to report discrimination, depression symptoms, and attempted suicides. Lack of self-acceptance of LGBT identity was associated with depression symptoms among transgender individuals.
\end{abstract}

Key words: depression symptoms; discrimination; LGBT; LGBT identity acceptance; transgender

\section{Introduction}

Transgender is an umbrella term for persons whose gender identity, gender expression, or behavior does not conform to that typically associated with the sex to which they were assigned at birth. ${ }^{1}$ While the lesbian, gay, bisexual, and transgender (LGBT) population overall bears a disproportionate burden of mental health issues relative to the general population, ${ }^{2-10}$ emerging evidence suggests that within the LGBT population the odds of depression symptoms are even higher among transgender individuals compared with nontransgender individuals. ${ }^{11-15}$ Findings based on a major survey conducted in 2009 by MassEquality revealed that heterosexual respondents had the lowest rates of depression and suicide ideation, followed by gay and lesbian respondents, bisexual respondents, and transgender respondents, of whom $30.8 \%$ had contemplated suicide. ${ }^{15}$ The corresponding prevalence of suicide ideation was even higher in the

${ }^{1}$ Center for Reducing Health Disparities, College of Public Health, University of Nebraska Medical Center, Omaha, Nebraska.

${ }^{2}$ Department of Health Promotion, Social and Behavioral Health, College of Public Health, University of Nebraska Medical Center, Omaha, Nebraska.

${ }^{3}$ Department of Sociology \& Anthropology, University of Nebraska at Omaha, Omaha, Nebraska.

${ }^{4}$ Department of Health Promotion and Sexology, School of Public Health, Curtin University, Perth, Australia.

${ }^{5}$ Department of Nutrition and Health Services, College of Education and Human Sciences, University of Nebraska-Lincoln, Lincoln, Nebraska.

${ }^{6}$ Eastern Nebraska Community Action Partnership (ENCAP), Omaha, Nebraska.

${ }^{7}$ School of Health, Physical Education, and Recreation, University of Nebraska at Omaha, Omaha, Nebraska.

*Address correspondence to: Dejun Su, PhD, Center for Reducing Health Disparities, College of Public Health, University of Nebraska Medical Center, Omaha, NE 681984340, E-mail: dejun.su@unmc.edu

(C) Dejun Su et al. 2016; Published by Mary Ann Liebert, Inc. This Open Access article is distributed under the terms of the Creative Commons License (http://creativecommons.org/licenses/by/4.0), which permits unrestricted use, distribution, and reproduction in any medium, provided the original work is properly credited. 
National Transgender Discrimination Survey (NTDS) where $41 \%$ of transgender respondents reported ever attempting suicide in their life compared with $1.6 \%$ among the general population in the United States. ${ }^{16}$

The elevated odds of suicide attempt among transgender persons could be related to discrimination experienced by this population. Discrimination is an important risk factor of depression among transgender individuals. ${ }^{17}$ Clements-Nolle, Marx, and Katz ${ }^{18}$ found depression and gender-based discrimination to be independently associated with attempted suicide in their San Francisco-based study, in which 32\% of transgender participants had attempted suicide. According to data from NTDS, $63 \%$ of transgender individuals had experienced a serious act of discrimination, and nearly a quarter (23\%) had experienced three or more serious acts of discrimination, a level of discrimination which the study described as catastrophic. ${ }^{16}$ Transgender discrimination is a common experience across the United States in areas of public life, including housing, employment, accommodation, the workplace, and healthcare settings. ${ }^{19-21}$ Nearly one in five (19\%) respondents in the NTDS reported being refused medical care due to their gender identity, and half reported that they had to teach their healthcare providers about transgender care. Over one in four $(28 \%)$ had postponed healthcare due to discrimination, and nearly half $(48 \%)$ had postponed healthcare due to affordability. The study found that the transgender population had lower income than the general population and nearly four times more likely to have a household income of under $\$ 10,000 /$ year. ${ }^{16}$

In a heteronormative society, nontraditional gender identity and sexuality influence self-esteem. Internalized transphobia, a discomfort with one's own transgenderism as a result of internalizing society's normative gender expectations, can negatively affect health outcomes among transgender people. ${ }^{22}$ For many transgender individuals, feelings of shame, isolation, anger, sadness, loss, and even self-rejection or requestioning of one's identity can lead to depression symptoms, which in turn might be associated with high odds of sexual behavior. ${ }^{23}$ On the other hand, identity acceptance and coping strategies can be protective factors in the face of discrimination, ${ }^{24}$ but when positive reinforcement and social support are lacking, the ability to deal with discrimination and prejudice can be significantly impaired. ${ }^{25}$

This study describes the experience of a sample of gender and sexual minority adults in Nebraska. The study has two aims: the first is to assess whether trans- gender identity is associated with an elevated probability of reported discrimination, depression symptoms, and suicide attempts compared with nontransgender LGB individuals; the second is to determine if LGBT identity acceptance is associated with a lower probability of depression symptoms in transgender and nontransgender LGB individuals.

\section{Methods}

Data

The data utilized in the current study were collected in 2010 through an online survey for ease of recruitment over the large geographical area of Nebraska. The survey was approved by the Institutional Review Board at the University of Nebraska Medical Center in 2010. Before the survey, the study team engaged a number of community members and organizations from across the state to better understand the needs of the LGBT community and how research might be helpful in supporting those needs. The survey instruments were developed based on feedback and suggestions from interviewed community members using a communitybased participatory research (CBPR) approach. ${ }^{26,27}$ Participants were self-identified lesbian, gay, bisexual, and/or transgender persons over the age of 19. Through a multipronged recruitment strategy, involving e-mails, advertisements in LGBT-friendly publications and fliers at public venues, and nonincentivized respondentdriven sampling, 770 LGBT Nebraskans participated in the study. ${ }^{28}$

Participants were directed to a university-hosted website to complete the survey, where an introductory page informed them of the aims of the study. Participants were informed of their rights on the website and agreed to participate if they met the study criteria (living, working, or accessing services in Nebraska, being 19 years or older, and self-identifying as LGBT). The 67-item survey took on average $30 \mathrm{~min}$ to complete and participants could choose to not answer any question about which they felt uncomfortable by selecting "Prefer not to answer." Participants were given the option to receive a $\$ 5$ gift card on completion of the survey. Upon opting to receive the gift card, participants were taken to a separate page not linked to the survey to provide their mailing address. Only about half of participants chose to collect the incentive.

\section{Measures}

This analysis includes transgender identity, basic sociodemographic information, basic health indicators, and 
measures of discrimination, depression symptoms, suicide attempts, and LGBT identity acceptance. Transgender identity was based on the following question: Do you identify as transgender/transsexual or gender nonconforming? (binary; yes vs. no) Sociodemographic and economic status variables included age (a continuous variable ranging from 19 to 70 years), race (binary; white vs. nonwhite), rural (binary; rural vs. urban), marital status (binary; married or partnered vs. all other marital status categories), education (binary; no college degree vs. college degree or higher), income (binary; annual household income $<\$ 25,000$ vs. annual household income $\geq \$ 25,000$ ), and employment status (binary; employed for wages vs. unemployed). Rural residence was defined as residential locations other than the metro areas of Omaha and Lincoln, the two major cities in Nebraska.

The following health indicators were included in this analysis: self-rated health (binary; excellent/very good vs. good/fair/poor), HIV infection status (binary; positive vs. negative or prefer not to answer), smoking daily (binary; yes vs. no or prefer not to answer), and current use of illicit drugs (binary; yes vs. no or prefer not to answer).

Discrimination was measured using a 15 -item scale that assessed the frequency of reported discrimination, which was initially developed by Wright et al. in their study of sexual minority youths in Indiana. ${ }^{29}$ Items included questions such as "Were you treated unfairly by employers, bosses, and supervisors because of your LGBT status?" and "Did someone verbally insult or abuse you?" (the frequency was coded as never $=1$, once $=2$, twice $=3$, and thrice or more $=4$ ). Overall scores were derived by summing all coded responses with a range from 15 to 60 and an average score of 24 among all respondents; reliability was high $(\alpha=0.904)$. Individuals with a discrimination score above 24 were coded as reporting a high level of discrimination.

Depression symptoms were measured utilizing the Centers for Epidemiological Studies-Depression Scale (CES-D). ${ }^{30}$ The 20 -item scale asked participants to indicate how often each item had occurred for them in the past week. Statements included the following: "I felt lonely," I enjoyed life," and "I was happy." Options were ranked on a 4-point scale from "rarely or none of the time (less than 1 day)" to "most or all of the time (5-7 days)." Scores were calculated as per standard protocols, ranging from 0 to 60 , with high scores indicating greater depressive symptoms. Reliability for the scale in this study was high $(\mathrm{alpha}=0.929) .{ }^{30}$ Individuals who scored beyond a proposed clinical cutoff value of 16 were coded as 1 , indicating more depression symptoms.
Suicide attempts were assessed using a single-item question: Have you ever attempted suicide? (binary; yes vs. no). Self-acceptance of LGBT identity was measured using a scale typically used to measure internalized homophobia adapted from Wright et al. ${ }^{29}$ Instead of measuring internalized homophobia, the scale on self-acceptance of LGBT identity concerns the degree to which study participants rejected negative attitudes about sexual/gender minority identities. The 11-item scale included statements such as "I have a positive attitude about being LGBT" and "I often feel ashamed that I am LGBT." Participants indicated their agreement on a 5-point Likert scale from strongly disagree to strongly agree. Reliability for the scale was high (alpha $=0.805)$. Possible scores range from 11 to 55, with scores equal or above 44 coded as having a high level of selfacceptance of LGBT identity and scores below 44 as having a low level of self-acceptance of LGBT identity.

\section{Statistical analyses}

We first used $t$ - or chi-square tests to assess if there were significant differences between transgender and nontransgender respondents in demographics, socioeconomic status (SES), health behavior, reported discrimination, depression symptoms, LGBT identity acceptance, and attempted suicide. This was followed by a logit model, in which we related perceiving aboveaverage discrimination to transgender identity after controlling for demographics, SES, self-rated health, HIV status, and health behavior. We then ran two additional logit models, in which we examined how transgender identity, reported discrimination, LGBT identity acceptance, and other selected explanatory variablesdemographics, SES, self-rated health, HIV status, and health behavior-could help predict the odds of depression symptoms and suicide attempt, respectively. Finally, we conducted a cross-tabulation and chi-square test to assess the association between LGBT identity acceptance and depression symptoms, respectively, among transgender and nontransgender respondents. In all regression analyses, we also presented information on model fitness as indicated by the percentage of cases predicated correctly by the model and Cox and Snell R Square. ${ }^{31}$ Statistical analyses were conducted using SPSS 21.0.

\section{Results}

We first compared responses to selected variables between respondents who identified as transgender and those who identified otherwise (Table 1). Transgender respondents on average had lower socioeconomic status 
Table 1. A Description of the Sample by Transgender Status ( $n=767)$

\begin{tabular}{|c|c|c|c|c|c|c|c|}
\hline \multirow[b]{2}{*}{ Variables } & \multicolumn{2}{|c|}{ Transgender } & \multicolumn{2}{|c|}{ Nontransgender } & \multirow{2}{*}{$\frac{\text { T-test or chi-square }}{p}$} & \multicolumn{2}{|c|}{ Total sample } \\
\hline & Mean or \% & $N$ & Mean or \% & $N$ & & Mean or \% & $N$ \\
\hline Age (mean years) & 36.3 & 89 & 36.0 & 665 & 0.810 & 36.0 & 754 \\
\hline Race & & & & & 0.224 & & \\
\hline White & 86.8 & 79 & 91.9 & 614 & & 91.3 & 691 \\
\hline Nonwhite & 13.2 & 12 & 8.1 & 54 & & 8.7 & 66 \\
\hline Residence & & & & & 0.729 & & \\
\hline Urban (Lincoln/Omaha) & 90.4 & 75 & 89.1 & 548 & & 89.3 & 623 \\
\hline Rural (not from Lincoln/Omaha) & 9.6 & 8 & 10.9 & 67 & & 10.7 & 75 \\
\hline Marital status & & & & & 0.516 & & \\
\hline Married or partnered & 52.2 & 47 & 55.9 & 377 & & 55.4 & 424 \\
\hline Other & 47.8 & 43 & 44.1 & 298 & & 44.6 & 341 \\
\hline Education & & & & & 0.012 & & \\
\hline No college degree & 59.3 & 54 & 36.4 & 306 & & 47.1 & 360 \\
\hline College degree or higher & 40.7 & 37 & 63.6 & 370 & & 52.9 & 407 \\
\hline Income & & & & & 0.090 & & \\
\hline Annual Household $\$<25,000$ & 38.2 & 34 & 29.4 & 196 & & 32.7 & \\
\hline Annual Household $\$ \geq 25,000$ & 61.8 & 55 & 70.6 & 471 & & & \\
\hline Employment status & & & & & 0.035 & & \\
\hline Employed for wages & 62.6 & 57 & 73.2 & 495 & & 72.0 & 552 \\
\hline Unemployed & 37.4 & 34 & 26.8 & 181 & & 28.0 & 215 \\
\hline Self-rated health & & & & & 0.071 & & \\
\hline Excellent/very good & 54.4 & 49 & 64.2 & 433 & & 63.1 & 482 \\
\hline Good/fair/poor & 45.6 & 41 & 35.8 & 241 & & 36.9 & 282 \\
\hline HIV infection status & & & & & 0.032 & & \\
\hline Negative or prefer not to answer & 100.0 & 90 & 95.1 & 639 & & 95.5 & 729 \\
\hline Positive & 0.0 & 0 & 4.9 & 33 & & 4.5 & 33 \\
\hline Smoking daily & & & & & 0.930 & & \\
\hline Yes & 16.7 & 15 & 16.2 & 109 & & 16.4 & 124 \\
\hline No or prefer not to answer & 83.3 & 75 & 83.8 & 563 & & 83.6 & 638 \\
\hline Current use of illicit drugs & & & & & 0.802 & & \\
\hline Yes & 70.3 & 64 & 71.6 & 484 & & 28.6 & 220 \\
\hline No or prefer not to answer & 29.7 & 27 & 28.4 & 192 & & 71.4 & 550 \\
\hline Level of discrimination ${ }^{a}$ & & & & & 0.083 & & \\
\hline Low & 56.0 & 51 & 65.3 & 439 & & 64.2 & 490 \\
\hline High & 44.0 & 40 & 34.7 & 233 & & 35.8 & 273 \\
\hline Depression symptoms ${ }^{\mathrm{b}}$ & & & & & $<0.001$ & & \\
\hline Fewer & 46.2 & 42 & 66.6 & 447 & & 64.2 & 489 \\
\hline More & 53.8 & 49 & 33.4 & 224 & & 35.8 & 273 \\
\hline Ever attempted suicide & & & & & $<0.001$ & & \\
\hline Yes & 37.6 & 32 & 15.9 & 106 & & 18.6 & 138 \\
\hline No & 62.4 & 53 & 84.1 & 559 & & 81.4 & 602 \\
\hline Self-acceptance of LGBT identity ${ }^{c}$ & & & & & 0.107 & & \\
\hline Low & 53.8 & 49 & 44.9 & 302 & & 45.9 & 351 \\
\hline High & 46.2 & 42 & 55.1 & 371 & & 54.1 & 413 \\
\hline Total number of cases & & 91 & & 676 & & & 767 \\
\hline Percentage & & 11.9 & & 88.1 & & & 100.0 \\
\hline
\end{tabular}

${ }^{\mathrm{a}}$ Based on a 15 -item scale with scores of 0-24 being coded as Low and 25-60 coded as High.

b Based on a 20-item Centers for Epidemiological Studies-Depression scale with scores $\leq 16$ coded as Fewer and scores $>16$ as More.

${ }^{\mathrm{C}}$ Based on a 11 -item scale with scores $\geq 44$ coded as having a high level of self-acceptance of LGBT identity and scores $<44$ as having a low level of self-acceptance of LGBT identity.

than the rest of the sample. About $40.7 \%$ of transgender respondents received a bachelors or higher degree compared with $54.7 \%$ of nontransgender respondents $(p=0.012)$. Consistent with the gap in educational attainment, transgender respondents were also less likely to be employed for wages than the rest of the sample (63\% vs. $73 \%, p=0.035)$. Another notable difference is that relative to nontransgender respondents in the sample, transgender respondents were less likely to report being HIV positive $(p=0.032)$.

The most significant differences between transgender and nontransgender respondents, however, were found in past week depressive symptoms and a life history of attempted suicide. Transgender respondents were 
more likely to report depression symptoms ( $53.9 \%$ vs. $33.4 \%, p<0.001)$ in the past week, and the proportion of transgender respondents who reported attempted suicide was over twice that of nontransgender respondents $(37.7 \%$ and $15.9 \%$, respectively, $p<0.001)$.

We next assessed the relationship between our selected explanatory variables and perception of aboveaverage discrimination in the sample (Table 2). Transgender respondents were more likely than nontransgender respondents to report high levels of reported discrimination. After controlling for the effects of age,

\begin{tabular}{|c|c|c|}
\hline Explanatory variables & $\begin{array}{l}\text { Odds } \\
\text { ratio }\end{array}$ & $\begin{array}{l}\text { 95\% Confidence } \\
\text { interval }\end{array}$ \\
\hline \multicolumn{3}{|l|}{ Transgender identity } \\
\hline Nontransgender & 1.00 & \\
\hline Transgender & $2.09^{a}$ & $(1.28,3.42)$ \\
\hline Age & 1.01 & $(1.00,1.03)$ \\
\hline \multicolumn{3}{|l|}{ Race } \\
\hline Nonwhite & 1.00 & \\
\hline White & 0.82 & $(0.48,1.41)$ \\
\hline \multicolumn{3}{|l|}{ Residence } \\
\hline Urban (Lincoln/Omaha) & 1.00 & \\
\hline Rural (not from Lincoln/Omaha) & 0.82 & $(0.47,1.43)$ \\
\hline \multicolumn{3}{|l|}{ Marital status } \\
\hline Other & 1.00 & \\
\hline Married or partnered & 1.20 & $(0.86,1.69)$ \\
\hline \multicolumn{3}{|l|}{ Education } \\
\hline No college degree & 1.00 & \\
\hline College degree or higher & 1.18 & $(0.82,1.69)$ \\
\hline \multicolumn{3}{|l|}{ Income } \\
\hline Annual household $\$ \geq 25,000$ & 1.00 & \\
\hline Annual household $\$<25,000$ & 1.01 & $(0.68,1.50)$ \\
\hline \multicolumn{3}{|l|}{ Employment status } \\
\hline Unemployed & 1.00 & \\
\hline Employed for wages & 1.01 & $(0.68,1.50)$ \\
\hline \multicolumn{3}{|l|}{ Self-rated health } \\
\hline Good/fair/poor & 1.00 & \\
\hline Excellent/very good & 0.92 & $(0.65,1.29)$ \\
\hline \multicolumn{3}{|l|}{ HIV infection status } \\
\hline Negative or prefer not to answer & 1.00 & \\
\hline Positive & 1.59 & $(0.75,3.38)$ \\
\hline \multicolumn{3}{|l|}{ Smoking daily } \\
\hline No or prefer not to answer & 1.00 & \\
\hline Yes & $1.73^{\mathrm{b}}$ & $(1.11,2.70)$ \\
\hline \multicolumn{3}{|l|}{ Current use of illicit drugs } \\
\hline No or prefer not to answer & 1.00 & \\
\hline Yes & 1.45 & $(1.00,2.10)$ \\
\hline \multicolumn{3}{|l|}{ Self-acceptance of LGBT identity } \\
\hline Low & 1.00 & \\
\hline High & 1.04 & $(0.75,1.45)$ \\
\hline \multicolumn{3}{|l|}{ Model Information } \\
\hline Number of cases included & & 670 \\
\hline Percentage predicted correctly & & 65.4 \\
\hline Cox and Snell R Square & & 0.05 \\
\hline
\end{tabular}

${ }_{b}^{a} p<0.01$.

${ }^{\mathrm{b}} p<0.05$ race, SES, self-rated health, and other selected variables, the odds for transgender respondents to report aboveaverage discrimination were more than twice the odds for nontransgender respondents $(p<0.01)$. Smoking on a daily basis was associated with higher odds of perceiving above-average discrimination $(\mathrm{OR}=1.73, p<0.05)$.

Transgender identity was associated with higher odds of depression symptoms and suicide attempt (Table 3). After controlling for selected variables in our analysis, the odds for transgender respondents to report high levels of depression symptoms were $84 \%$ higher than nontransgender respondents $(p<0.05)$. Similar findings can also be observed in the case of attempting to commit suicide $(\mathrm{OR}=2.68, p<0.01)$.

Besides transgender identity, several of our selected explanatory variables were also associated with the odds of depression symptoms. Respondents who were married or partnered at the time of the survey were less likely to report high depression symptoms compared with the rest of the sample $(\mathrm{OR}=0.59, p<0.01)$. Having an annual household income of less than $\$ 25,000$ was associated with higher odds of depression symptoms $(\mathrm{OR}=1.86$, $p<0.01)$. Excellent or very good self-rated health was associated with lower odds of depression symptoms $(\mathrm{OR}=$ $0.31, p<0.001)$. Respondents who were currently using illicit drugs at the time of the survey were more likely to report depression symptoms $(\mathrm{OR}=1.62, p<0.05)$.

The two variables that showed the most significant association with depression symptoms were reported discrimination and LGBT identity acceptance. Respondents who perceived above-average discrimination were more likely to report depression symptoms $(\mathrm{OR}=2.59$, $p<0.001)$. LGBT identity acceptance was negatively associated with depression symptoms. Respondents with higher identity acceptance had significantly lower odds of reporting depression symptoms compared with those with low identity acceptance $(\mathrm{OR}=0.45, p<0.001)$.

In terms of the odds of attempted suicide, having a household income of less than $\$ 25,000$ was associated with higher odds of attempt to commit suicide $(\mathrm{OR}=1.64, p<0.05)$. Relative to the rest of the sample, being employed was associated with lower odds of suicide attempt $(\mathrm{OR}=0.60, p<0.05)$. Respondents who perceived above-average discrimination had over three times the odds of attempted suicide $(\mathrm{OR}=3.57, p<0.001)$.

For both transgender and nontransgender respondents, a high level of identity acceptance was associated with fewer depression symptoms (Table 4). One notable difference between the two groups, however, lies in how identity acceptance was associated with 
Table 3. Multivariate Logistic Regression on Mental Health Expressed as Odds Ratios

\begin{tabular}{|c|c|c|c|c|}
\hline \multirow[b]{2}{*}{ Explanatory variables } & \multicolumn{2}{|c|}{ More depression symptoms } & \multicolumn{2}{|c|}{ Ever attempted suicide } \\
\hline & Odds ratio & $95 \% \mathrm{Cl}$ & Odds ratio & $95 \% \mathrm{Cl}$ \\
\hline \multicolumn{5}{|l|}{ Transgender identity } \\
\hline Nontransgender & 1.00 & & 1.00 & \\
\hline Transgender & $1.84^{\mathrm{a}}$ & {$[1.06,1.17]$} & $2.68^{\mathrm{b}}$ & $(1.31,5.13)$ \\
\hline Age & 0.99 & {$[0.97,1.00]$} & 0.99 & $(0.97,1.01)$ \\
\hline \multicolumn{5}{|l|}{ Race } \\
\hline Nonwhite & 1.00 & & 1.00 & \\
\hline White & 1.15 & {$[0.64,2.07]$} & 0.84 & $(0.44,1.62)$ \\
\hline \multicolumn{5}{|l|}{ Residence } \\
\hline Urban (Lincoln/Omaha) & 1.00 & & 1.00 & \\
\hline Rural (Not from Lincoln/Omaha) & 1.19 & {$[0.67,2.10]$} & 0.96 & $(0.47,1.94)$ \\
\hline \multicolumn{5}{|l|}{ Marital status } \\
\hline Other & 1.00 & & 1.00 & \\
\hline Married or partnered & $0.59^{c}$ & {$[0.41,0.86]$} & 0.91 & $(0.58,1.41)$ \\
\hline \multicolumn{5}{|l|}{ Education } \\
\hline No college degree & 1.00 & & 1.00 & \\
\hline College degree or higher & 0.77 & {$[0.52,1.14]$} & 0.69 & $(0.43,1.10)$ \\
\hline \multicolumn{5}{|l|}{ Income } \\
\hline Annual household $\$ \geq 25,000$ & 1.00 & & 1.00 & \\
\hline Annual household $\$<25,000$ & $1.86^{\mathrm{c}}$ & {$[1.24,2.79]$} & $1.64^{\mathrm{a}}$ & $(1.02,2.66)$ \\
\hline \multicolumn{5}{|l|}{ Employment status } \\
\hline Unemployed & 1.00 & & 1.00 & \\
\hline Employed for wages & 0.68 & {$[0.45,1.03]$} & $0.60^{\mathrm{a}}$ & $(0.37,0.96)$ \\
\hline \multicolumn{5}{|l|}{ Self-rated health } \\
\hline Good/fair/poor & 1.00 & & 1.00 & \\
\hline Excellent/very good & $0.31^{\mathrm{b}}$ & {$[0.21,0.45]$} & 0.69 & $(0.45,1.08)$ \\
\hline \multicolumn{5}{|l|}{ HIV infection status } \\
\hline Negative or prefer not to answer & 1.00 & & 1.00 & \\
\hline Positive & 1.27 & {$[0.56,2.89]$} & 2.26 & $(0.95,5.41)$ \\
\hline \multicolumn{5}{|l|}{ Smoking daily } \\
\hline No or prefer not to answer & 1.00 & & 1.00 & \\
\hline Yes & 0.75 & {$[0.45,1.24]$} & 1.19 & $(0.69,2.08)$ \\
\hline \multicolumn{5}{|l|}{ Current use of illicit drugs } \\
\hline No or prefer not to answer & 1.00 & & 1.00 & \\
\hline Yes & $1.62^{\mathrm{a}}$ & {$[1.08,2.44]$} & 0.93 & $(0.57,1.51)$ \\
\hline \multicolumn{5}{|l|}{ Reported discrimination } \\
\hline Low & 1.00 & & 1.00 & \\
\hline High & $2.59^{\mathrm{b}}$ & {$[1.77,3.77]$} & $3.17^{\mathrm{b}}$ & $(2.05,4.91)$ \\
\hline \multicolumn{5}{|l|}{ Self-acceptance of LGBT identity } \\
\hline Low & 1.00 & & 1.00 & \\
\hline High & $0.45^{\mathrm{b}}$ & {$[0.31,0.65]$} & 1.20 & $(0.77,1.86)$ \\
\hline \multicolumn{5}{|l|}{ Model Information } \\
\hline Number of cases included & \multicolumn{2}{|c|}{669} & \multicolumn{2}{|c|}{655} \\
\hline Percentage predicted correctly & \multicolumn{2}{|c|}{72.9} & \multicolumn{2}{|c|}{82.7} \\
\hline Cox and Snell R Square & \multicolumn{2}{|c|}{0.20} & \multicolumn{2}{|c|}{0.11} \\
\hline
\end{tabular}

depression symptoms. Among nontransgender respondents, $42.2 \%$ of the respondents with low selfacceptance of LGBT identity reported more depression symptoms compared with $71.4 \%$ among transgender respondents. This was also confirmed by the adjusted odds ratios after controlling for the effect of selected explanatory variables. Among transgender respondents, relative to those with a low level of self-acceptance of
LGBT identity, the adjusted odds for respondents with a high level of self-acceptance to report more depression symptoms were $0.04(p<0.001)$ compared with $0.53(p=0.002)$ among nontransgender respondents.

\section{Discussion}

Mental health is an essential dimension of overall health, and mental disorders represent one of the leading causes 
Table 4. Self-Acceptance of LGBT Identity and Depression Symptoms in the Past Week Among Transgender and Nontransgender Respondents

\begin{tabular}{|c|c|c|c|c|c|c|}
\hline \multirow[b]{2}{*}{ Self-Acceptance Level } & \multicolumn{3}{|c|}{ Transgender } & \multicolumn{3}{|c|}{ Nontransgender } \\
\hline & Not depressed & Depressed & Total & Not depressed & Depressed & Total \\
\hline Low (\%) & $14(28.6)$ & $35(71.4)$ & $49(100)$ & $174(57.8)$ & $127(42.2)$ & $301(100 \%)$ \\
\hline High (\%) & $28(66.7)$ & $14(33.3)$ & $42(100)$ & $272(73.7)$ & $97(26.3)$ & 369 (100\%) \\
\hline Chi-square & & 13.2 & & & 18.8 & \\
\hline$p$ & & $<0.001$ & & & $<0.001$ & \\
\hline \multicolumn{7}{|c|}{ Adjusted odds ratios on depression symptoms in the past week } \\
\hline Low & 1.0 & (reference) & & & 0 (reference) & \\
\hline High & 0.04 & b $(0.01,0.25)$ & & & $3^{c}(0.36,0.79)$ & \\
\hline Number of cases & & 78 & & & 591 & \\
\hline Percentage predicated correctly by the model & & 80.8 & & & 74.1 & \\
\hline Cox and Snell R Square & & 0.46 & & & 0.20 & \\
\hline
\end{tabular}

${ }^{a}$ The odds ratios associated with self-acceptance of LGBT identity were adjusted for the effect age, race, rural residence, marital status, education, income, employment status, self-rated health, HIV status, daily smoking status, use of illicit drugs, and reported discrimination. ${ }^{\mathrm{b}} p<0.001$.

${ }^{c} p<0.01$.

of premature death and disability across the globe. ${ }^{32,33}$ Although the LGBT population makes up a small percentage of the overall population, the mental health needs of those who identify as gender and sexual minorities are substantial. ${ }^{2-10}$ Current research on LGBT mental health is rather limited with even less research focused on transgender individuals. ${ }^{34}$ An important barrier is that for now there has been no systematic collection of data on sexual orientation and gender identity at the national level. For example, of the 50 states participating in the Behavioral Odds Factor Surveillance System (BRFSS), only 27 states have, on their own initiative, begun asking questions about sexual orientation, and even fewer states have started to ask questions on gender identity. ${ }^{35}$

Based on survey data collected from respondents who self-identified as sexual or gender minorities in Nebraska, the present study compared transgender and nontransgender respondents in terms of reported discrimination, depression symptoms, and suicide attempts. Relative to nontransgender respondents, transgender individuals were at higher odds of reporting discrimination, depression symptoms, and attempted suicides. Moreover, the elevated odds associated with transgender identity were robust after controlling for selected variables in demographics, SES, health behavior, self-rated health, and identity acceptance.

The high prevalence of depression symptoms and attempted suicides among transgender respondents in the study could be related to the alarming rates of exposure to discrimination in this population. Based on analysis of suicide attempt and its predictors among 515 transgender individuals, one study reported that genderbased discrimination and gender-based victimization were independently associated with attempted suicide. ${ }^{18}$ Discrimination and prejudice against transgender people are pervasive. Recent evidence from Virginia suggests that transgender Virginians experienced widespread discrimination in healthcare, employment, and housing. ${ }^{19}$ Over $40 \%$ of transgender respondents in our study reported a high level of discrimination, pointing to a need to identify the sources of discrimination and address the issue through legislation and public education. Hate crime legislation is needed to increase protection of transgender individuals from discrimination, rejection, and violence. ${ }^{21,36}$ In addition, interventions to increase public awareness of mental health disparities related to transgender persons should emphasize the importance of changing community attitudes to foster greater acceptance. State-level structural stigma was associated with lifetime suicide attempts among transgender adults based on recent findings from a nationwide sample. ${ }^{37}$

Findings from this study reinforce the urgency of suicide prevention among transgender individuals. Among transgender respondents, $37.7 \%$ reported attempted suicide compared with $15.9 \%$ among the rest of the sample. This is consistent with corresponding findings from previous studies where a substantial percentage of transgender persons reported suicide ideation. ${ }^{15,16,18}$ Certain groups of transgender persons may be even more vulnerable to suicide ideation, including those on the female-to-male spectrum, those with a history of psychiatric hospitalizations, and those who experienced transgender-related violence. ${ }^{38}$ Limited access to competent healthcare services is a critical barrier to suicide prevention among transgender persons, and the economic disadvantage disproportionately experienced 
by transgender individuals can further restrict timely access to needed care. Furthermore, there is a gap between the healthcare needs of transgender individuals and the supply of care providers who have the sensitivities and expertise to provide culturally relevant care. ${ }^{39}$

One interesting finding from this study concerns the association between identity acceptance and reduced depression symptoms. Even after controlling for selected variables on transgender identity, demographics, SES, self-rated health, and health behavior, respondents who indicated a higher level of identity acceptance were substantially less likely to report depression symptoms. Furthermore, our study provides preliminary evidence that lack of identity acceptance might pose more harm to mental health among transgender individuals than among nontransgender individuals. Depression symptoms among sexual and gender minorities, including transgender persons, may relate to their own perception of gender identity and/or sexual orientation. Exposure to stigma, prejudice, and discrimination could lead to questioning, rejection, and internalized shame of their own sexuality, constituting a significant source of depression symptoms. ${ }^{40}$ Programs aiming to improve identity acceptance among transgender persons could potentially help these individuals better cope with experiences of stigma and discrimination and thus reduce the odds of depression symptoms.

\section{Limitations}

Several limitations of the study are noteworthy. First, while the use of an online survey provides convenience to respondents and helps lower the cost of the study, it precludes those sexual and gender minority individuals who do not have access to computers or the internet. Since the recruitment effort, including study advisement, was primarily focused in the Omaha metropolitan area, ${ }^{28}$ LGBT individuals who live in the rural areas of Nebraska might have been less represented in our sample. Second, key measurements used in the study such as reported discrimination, depression symptoms, and attempted suicides were all based on self-report data. As a result, recall bias might be an issue in some of the data we used. Finally, of the 767 subjects in the survey, only 91 identified as transgender. These respondents also included those who self-identified as gender-nonconforming LGB individuals. The limited sample size prevented us from conducting some further analysis such as to examine how specific transgender types (e.g., female-male vs. male-female transitions) might be related to the mental health outcomes discussed in the study.
Despite these limitations, this study represents a rare effort in assessing mental health outcomes among transgender persons in a relatively conservative Midwestern state. The findings indicate that relative to nontransgender LGB individuals, transgender individuals were more likely to report discrimination, depression symptoms, and attempted suicides. Much of the existing health disparities research concerning transgender individuals has been based on comparisons between transgender and cisgender individuals broadly and not within the LGBT community. ${ }^{41,42}$ Our findings show that even within the already marginalized LGBT community, transgender individuals have worse mental health relative to their cisgender LGB peers.

\section{Conclusions}

Transgender identity was associated with higher odds of reported discrimination, depression symptoms, and attempted suicides. There was a positive association between reported discrimination and depression symptoms among the LGBT population in Nebraska. Self-acceptance of LGBT identity was associated with fewer depression symptoms and this was especially the case among transgender individuals. Protective legislation and public education on gender identity can potentially reduce discrimination against transgender individuals, which is a needed step forward to create a social environment that fosters understanding and respect across social and cultural groups, irrespective of gender identity and sexual orientation.

\section{Author Disclosure Statement}

No competing financial interests exist.

\section{References}

1. American Psychological Association. Answers to your questions about Transgender people, gender identity, and gender expression. 2014:1-6. Available at www.apa.org/topics/sexuality/transgender.pdf. Accessed April 27, 2014.

2. Meyer IH. Prejudice, social stress, and mental health in lesbian, gay, and bisexual populations: conceptual issues and research evidence. Psychol Bull. 2003;129:674-697.

3. Russell ST, Ryan C, Toomey RB, et al. Lesbian, gay, bisexual, and transgender adolescent school victimization: implications for young adult health and adjustment. J School Health. 2011;81:223-230.

4. Burgess D, Tran A, Lee R, Van Ryn M. Effects of reported discrimination on mental health and mental health services utilization among Gay, Lesbian, Bisexual and Transgender persons. J LGBT Health Res. 2007;3:1-14.

5. Cochran SD, Sullivan JG, Mays VM. Prevalence of mental disorders, psychological distress, and mental services use among lesbian, gay, and bisexual adults in the United States. J Consult Clin Psych. 2003;71:53-61.

6. Matthews AK, Hughes TL, Johnson T, et al. Prediction of depressive distress in a community sample of women: the role of sexual orientation. Am J Public Health. 2002;92:1131-1139.

7. Cochran SD, Mays VM. Relation between psychiatric syndromes and behaviorally defined sexual orientation in a sample of the US population. Am J Epidemiol. 2000;151:516-523. 
8. Marshal MP, Dietz LD, Friedman MS, et al. Suicidality and depression symptoms disparities between sexual minority and heterosexual youth: a meta-analytic review. J Adolescent Health. 2011;49:115-123.

9. Institute of Medicine. The Health of Lesbian, Gay, Bisexual, and Transgender People: Building a Foundation for Better Understanding. Washington, DC: The National Academies Press, 2011.

10. Addis S, Davies M, Greene G, et al. The health, social care and housing needs of lesbian, gay, bisexual and transgender older people: a review of the literature. Health Soc Care Community. 2009;17:647-658.

11. Fredriksen-Goldsen $\mathrm{Kl}$, et al. Physical and mental health of transgender older adults: an at-odds and underserved population. Gerontologist. 2014;54:488-500.

12. Persson $D$. Unique challenges of transgender aging: implications from the literature. J Gerontol Soc Work. 2009;52:633-646.

13. Witten TM, Eyler AE. Gay, lesbian, bisexual, and transgender aging: challenges in research, practice, and policy. Baltimore: Johns Hopkins University Press, 2012.

14. Witten TM. Transgender aging: an emerging population and an emerging need. Rev Sexol. 2003;12:15-20.

15. Landers S, Gilsanz P. The Health of Lesbian, Gay, Bisexual, and Transgendered Persons in Massachusetts. Massachusetts Department of Public Health. 2009, pp. 1-19. Available at www.mass.gov/eohhs/docs/dph/ commissioner/lgbt-health-report.pdf. Accessed December 20, 2013.

16. Grant JM, Mottet LA, Tanis J, et al. Injustice at Every Turn: A Report of the National Transgender Discrimination Survey. Washington, DC: National Center for Transgender Equality and National Gay and Lesbian Task Force. 2011, pp. 1-220. Available at http://endtransdiscrimination.org/ PDFs/NTDS_Report.pdf. Accessed December 20, 2013.

17. Rotondi N. Depression symptoms in trans people: a review of the odds factors. Intern J Trans. 2012;13:104-116.

18. Clements-Nolle K, Marx R, Katz M. Attempted suicide among Transgende persons: the influence of gender-based discrimination and victimization. J Homosexual. 2006;51:53-69.

19. Bradford J. Experiences of transgender-related discrimination and implications for health: results from the virginia transgender health initiative study. Am J Public Health. 2013;103:1820-1829.

20. Reback CJ, Simon P, Bemis C, Gatson B. The Los Angeles Transgender Health Study: Community Report. Los Angeles: University of California. 2001, pp. 1-35. Available at www.friendscommunitycenter.org/documents/ LA_Transgender_Health_Study.pdf. Accessed December 20, 2013.

21. Reisner, SL, Hughto JMW, Dunham EE, et al. Legal protections in public accommodations settings: a critical public health issue for transgender and gender-nonconforming people. Milbank Q. 2015;93:484-515.

22. Bockting W. Internalized transphobia. In: The International Encyclopedia of Human Sexuality. 2015, pp. 583-625.

23. Hoffman B. An overview of depression among transgender women. Depress Res Treat. 2014; 2014:9.

24. Sánchez FJ, Vilain E. Collective self-esteem as a coping resource for maleto-female transsexuals. J Couns Psychol. 2009;56:202-209.

25. Greenfield J. Coming out: the process of forming a positive identity. In: Fenway: Guide to Lesbian, Gay, Bisexual, and Transgender health. (Makadon HM). Philadelphia: American College of Physician. 2008, pp. 45-74.

26. Reece M, Dodge B. A study in sexual health applying the principles of community-based participatory research. Arch Sex Behav. 2004;33: 235-247.

27. Israel GE. Supporting transgender and sex reassignment issues: couple and family dynamics. J Couple Relat Ther. 2004;3:53-63.

28. McCarthy MA, Fisher CM, Irwin JA, et al. Using the minority stress model to understand depression in lesbian, gay, bisexual, and transgender individuals in Nebraska. J Gay Lesbian Mental Health. 2014;18:4, 346-360.

29. Wright E, Dye JD, Jiles ME, Marcello MK. Empowering Gay, Lesbian, and Bisexual youth: Findings from the Indiana youth access project. 1999

30. Radloff LS. The CES-D scale: a self-report depression symptoms scale for research in the general population. Appl Psychol Meas. 1977;1: 385-401.

31. Cox DR, Snell EJ. Analysis of Binary Data, 2nd ed. London: Chapman \& Hall, 1989.

32. Umberson D, Montez JK. Social relationships and health a flashpoint for health policy. J Health Soc Behav. 2010;51(1 Suppl):S54-S66.

33. Mathers C, Loncar D. Projections of Global Mortality and Burden of Disease from 2002 to 2030. PLoS Med. 2006;3:e442.
34. Boehmer U. Twenty years of public health research: inclusion of lesbian, gay, bisexual, and transgender populations. Am J Public Health. 2002;92:1125-1130.

35. The Fenway Institute. Gathering sexual orientation data on statewide behavioral odds factor surveillance surveys: a call to action for state. 2014: 1-16. Available at http://fenwayfocus.org/wp-content/uploads/2014/03/ BRFSS-brief-March-20-2014-final.pdf. Accessed April 27, 2015.

36. Lombardi EL, Wilchins RA, Priesing D, Malouf D. Gender violence: transgender experiences with violence and discrimination. J Homosex. 2001;42:89-101.

37. Perez-Brumer A, Hatzenbuehler ML, Oldenburg CE, Bockting W. Individual- and structural-level risk factors for suicide attempts among transgender adults. Behav Med. 2015;41:164-171.

38. Maguen S, Shipherd JC. Suicide odds among transgender individuals. Psychol Sexual. 2010;1:34-43.

39. Lombardi E. Enhancing transgender health care. Am J Public Health. 2001;91:869-972.

40. King M, Semlyen J, Tai SS, et al. A systematic review of mental disorder, suicide, and deliberate self harm in lesbian, gay and bisexual people. BMC Psychiatry. 2008;8:70.

41. Conron KJ, Scott G, Stowell GS, Landers SJ. Transgender health in Massachusetts: results from a household probability sample of adults. Am J Public Health. 2012;102:118-122.

42. Reisner SL, Conron KJ, Tardiff LA, Jarvi S, Gordon AR, Austin SB. Monitoring the health of transgender and other gender minority populations: Validity of natal sex and gender identity survey items in a U.S. national cohort of young adults. BMC Public Health. 2014;14:1224.

Cite this article as: Su D, Irwin JA, Fisher C, Ramos A, Kelley M, Mendoza DAR, Coleman JD (2016) Mental health disparities within the LGBT population: a comparison between transgender and nontransgender individuals, Transgender Health 1:1, 12-20, DOI: 10.1089/ trgh.2015.0001.

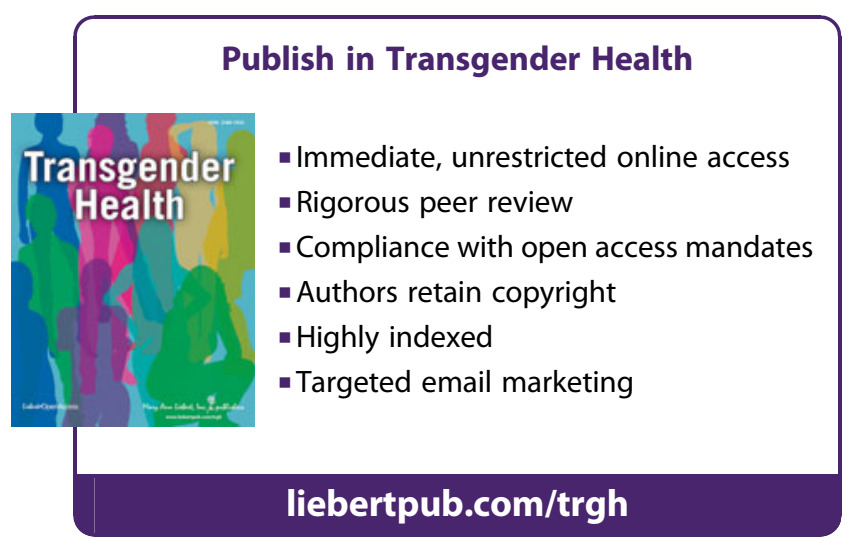

